Vol. 122006 pp. 125-130

\author{
Tomasz Radziewicz \\ Department of Geomorphology \\ E-mail: tomasz.radziewicz@wp.pl
}

\title{
POSSIBILITIES OF BALANCING OF ANTHROPOGENIC CHANGES OF RELIEF AND WATER CONDITIONS IN THE TATRA MOUNTAINS
}

\begin{abstract}
During its entire utilisation history - lasting several hundred years - the area of the Tatra Mountains underwent multidirectional anthropopressure. As the result, all components of their natural environment have been transformed, including relief and water conditions. The analysis of the literature on this topic conducted by the author, as well as his observations performed in the area, confirmed the assumption that transformations caused by human actions developed with varying intensity and admitted various forms depending on the area of action and the magnitude of means applied.

The transformation scale presented here estimates the influence of anthropopressure on the stability of the catchment area systems of larger Tatra streams, partial catchment areas of their confluents and selected slope surfaces.

In systems, where the limits of persistence were not exceeded, stability was ensured by natural processes compensating for the consequences of anthropopressure. In systems where stability was disturbed, planned preventive measures are necessary.
\end{abstract}

Key words: anthropopressure, relief, water conditions, Tatra Mountains, natural system, catchment area, system stability.

The transformation of the relief and water conditions in the Tatra Mountains, connected with human presence lasting already several hundred years, was developing with varying intensity and took on various forms depending on the area of human actions and on the intensity of human influence. Anthropopressure, in the broad sense of this word, underwent changes over the centuries. Some of its forms don't exist anymore (mining, metallurgy, timber industry, building materials industry), others changed their character (shepherding, forest husbandry), while the remaining ones took up a decisive role (tourism, settlements, long-distance effects).

Balancing of the environment transformation is not easy. Summing up the extent of the relief and water conditions transformations in quantitative categories is impossible with the current availability of the necessary materials. This is because: 
- In most cases of human activities in the past there is a lack of historical data that could determine the scope of the exploitation of the catchment area (the amount of the stone extracted from the quarry, the amount of the output of the mines, the number of trees cut, the volume of tapped water, etc.);

- Large part of transformations caused by human actions has been already compensated by nature, whose actions are superimposed, with varying intensity, on anthropopressure and are difficult to separate.

The estimate of the degree of transformation of water conditions is even more difficult than that of the relief. This is because:

- Water equilibrium of the catchment basin is a dynamic state and changes as the natural system components change; its current image is therefore not natural and has been shaped by the influence of the centuries-long transformation of the components by humans;

- Water conditions are characterised by relatively large persistence in form of plasticity; large differentiation of normal states during the year makes it difficult to recognise anthropopressure, whose value often does not exceed natural fluctuations;

- Changes of water conditions are not easy to observe due to their varied character - they can be rhythmic and directed, short- and long-lasting, regular and random, intrasystemic and intersystemic, quantitative and qualitative, etc.

Due to the impossibility of performing a quantitative summary of the scope of anthropogenic transformations, it was necessary to apply a qualitative method. The transformation scale proposed by the author estimates the influence of anthropopressure on the stability of natural systems (of various orders), formed by the catchment areas of larger Tatra streams, partial catchment areas of their confluents, and on a smaller scale - selected slope surfaces. The definition of the Tatra area or its fragments as a collection of systems is particularly justified in this situation. Large relief energy and high course of watersheds give namely a particular autonomy to mountain catchment areas. This doesn't mean, however, that such method of balancing can't be applied to terrains characterised by a different landscape type. This method is not specific to any landscape type.

In the most general approach the stability of a system is the result of its persistence. This, in turn, means that the system is able to preserve its structure under the impact of natural and anthropogenic disturbing factors or to return to the previous state - after a certain time, when the action of such factors and the disturbance of equilibrium stop. It is not, which is worth emphasising, a sign of invariability of the system; on the contrary, it indicates that a dynamic equilibrium dominates within the system.

The systems of catchment areas of Tatra streams exhibit persistence in form of plasticity, consisting in the appearance in these systems of several normal (or acceptable) states and in the ability of the systems to make transition from one state to another. Normal states include those formed 
under the impact of individual climatic (morphogenetic) seasons and when external disturbing factors are absent. Acceptable states, in turn, are those formed partly anthropogenically, in which the systems can still fulfil their natural-economic and ecologic functions with the required effectiveness.

Stability, as a complex property of a system, includes many of its features. A solid estimate requires taking into account a few of them.

The first of such properties of a system is its characteristic inertia. It consists in the appearance of changes in the system organisation or functioning only after a certain time of the duration of the external disturbances. Such delay in reaction is the result of various compensating and regulating mechanisms existing within the elements of the system.

The second property, elasticity, determines the rate, manner or degree in which the original features of the system are recreated after the disturbances had stopped. The relaxation period - in which the system returns to its initial condition - is of varying duration depending on the values of the parameters of the system elements. In mountain catchment areas it becomes longer as the elevation increases.

Equifinality consists in the achievement by the system, during its development, of the same final state with different initial conditions and in a different manner. In the case of the Tatra Mountains we are dealing with mixed equifinality, that is, the situation where after the disturbances some characteristic features return to the state identical with the initial state, while the remaining ones, to a state close to the initial state. In practice this means that some human influences leave permanent transformations, although they don't exceed the limits of persistence of the systems.

To ensure that the evaluation criteria following from the suggested method correspond fully to the character of the transformations, it is necessary to introduce an essential differentiation. Namely, when evaluating relief transformations, one should select surfaces or objects:

- Transformed, in which the impact of the causative factor agrees with the assumptions and the purpose of the terrain, and further develops its function.

- Degraded, in which the impact of the causative factor contradicts (or contradicted in the past) the current purpose of the terrain.

One should assume that each place (area) in the terrain under investigation can be assigned to one of these group. The basis for the assignment to the given group is the type of utilisation and the purpose of the terrain. It turns out that the majority of the catchment areas of Tatra streams is characterised by a specific duality. Partly, they are located in the mountains and partly in the Tatra foreland. Mountainous parts of the catchment areas, located within the national parks (TPN - Tatra National Park [Poland], TANAS - Tatra National Park [Slovakia]), belong to areas where nature protection has the priority and human activities are limited to tourism in the broad sense of this word and to scientific and teaching work (if a conflict between human activities and nature arises, all actions should yield to nature 
protection). Lower parts of the catchment areas are often occupied by agriculture or settlements, where humans have the priority.

Summing up this discussion one can accept that the relief transformations observed there can be categorised as degradations in the mountainous parts of the catchment areas and as transformations in the foreland areas.

In the case of the transformation of water conditions there are no reasons to treat the changes created in the lower parts of the catchment areas in a way different to that in the terrains of their Tatra parts. Waters are namely a very dynamic element of a system (they penetrate and combine the remaining elements and carry the disturbances); their characteristic features - both quantitative and qualitative - are derived from the state of the whole system. The changes, independently of their localisation, can disrupt the natural-economic and ecological functions fulfilled by the catchment areas. Because of that, for the transformations of water conditions (in their entirety) and for the degradation of the relief, joint criteria for the evaluation of the transformations have been suggested. The criteria are based on the evaluation of the consequences created by anthropopressure in the structure and functioning of the individual systems. They are shown in Table 1.

Table 1

Suggested criteria of evaluation of anthropogenic transformations of water conditions and of relief degradation in the Tatra Mountains

\begin{tabular}{|l|l|}
\hline $\begin{array}{l}\text { Degree of transfor- } \\
\text { mation }\end{array}$ & Character of transformation \\
\hline Very large & $\begin{array}{l}\text { Large, most often irreversible changes in ecosystems and/or economy } \\
\text { are created; the natural succession of the system occurs; stabilising } \\
\text { and renaturalising measures are required. }\end{array}$ \\
\hline Large & $\begin{array}{l}\text { The persistence of the system is exceeded; disturbance of equilibrium } \\
\text { and changes of the system structure occur, and new elements are } \\
\text { created or existing elements disappear (usually of low taxonomical } \\
\text { degree); changes of properties and quality of individual system ele- } \\
\text { ments occur; stabilising and renaturalising measures are required. }\end{array}$ \\
\hline Medium & $\begin{array}{l}\text { Changes remain within the limits of acceptable states; after the dis- } \\
\text { appearance of the causative factor the system returns to its normal } \\
\text { state. }\end{array}$ \\
\hline Small & Changes do not exceed the limits of normal states. \\
\hline Very small & $\begin{array}{l}\text { Changes are invisible or difficult to measure (the author accepts the } \\
\text { assumption that no human activity is without impact on the envi- } \\
\text { ronment). }\end{array}$ \\
\hline
\end{tabular}

Parts of the catchment areas situated outside the mountains exhibit features characteristic for natural-anthropogenic systems. Natural and anthropogenic components are mutually connected in such systems and act jointly, while the terrain fulfils a determined (planned) socio-economic function.

Such terrains are characterised by simplified structure and system functioning (both on the entire area and within the individual subsystems and system elements). Characteristic for them is also a change of biochemical 
cycles and a disturbance of chemical equilibrium, formed during the historical development of the systems (mostly due to the technogenic supply of many elements, in concentration many times higher than in natural conditions). The specific energy concentration occurring there is the result of energetic subventions from the built-up areas.

These terrains, transformed anthropogenically, have a limited capability for self-regulation. Stability is constantly maintained there by human actions, material components of the systems and creation of special construction. The share of natural and anthropogenic stabilising mechanisms varies, depending on the degree of technical transformation of the surface.

The proposed criteria of the evaluation of the degree of relief transformation are shown in Table 2.

Table 2.

\section{Suggested criteria of evaluation of anthropogenic relief transformations in the Tatra Mountains}

\begin{tabular}{|l|l|}
\hline $\begin{array}{l}\text { Degree of trans- } \\
\text { formation }\end{array}$ & Character of transformation \\
\hline Very large & $\begin{array}{l}\text { Changes in structure, composition and quantitative relations between } \\
\text { the components of the system occur; there is a lack of natural mecha- } \\
\text { nisms stabilising the structure and functioning of the system. }\end{array}$ \\
\hline Large & $\begin{array}{l}\text { Changes (simplification) of the way in which matter and energy flow } \\
\text { occur, without the occurrence of large changes of the system structure; } \\
\text { anthropogenic mechanisms stabilising the system dominate. }\end{array}$ \\
\hline Medium & $\begin{array}{l}\text { Disintegration of the internal relationships between the system compo- } \\
\text { nents occurs, which causes the disappearance of the natural stabilis- } \\
\text { ing mechanisms; co-existence of the natural and anthropogenic mecha- } \\
\text { nisms. }\end{array}$ \\
\hline Small & $\begin{array}{l}\text { The system is moved to a lower thermodynamic-information level with- } \\
\text { out a change in composition or in relationships between its components; } \\
\text { efficiency of the majority of natural processes, including stabilising ones, } \\
\text { decreases. }\end{array}$ \\
\hline Very small & Changes do not affect the structure or functioning of the system. \\
\hline
\end{tabular}

More detailed discussion of the scale and spatial distribution of the observed environmental transformations led the author to the conclusion that in the systems in which exceeding of the persistence limits is not observed, stability is ensured by natural processes, compensating for the results of anthropopressure (they are symptoms of normal functioning and evolution of the system). Among the most important of them are:

- Exogenic morphological processes,

- Ecological succession,

- Soil-forming processes,

- The process of self-cleaning of the waters,

- The phenomenon of soil sorption,

- The phenomenon of buffering occurring in the soil and in the rock medium. 
In the case of systems with disturbed stability it turns out that it is necessary to perform certain preventive measures. Recultivation and protection measures should aim at ensuring the persistence of utilisation of the local environment resources. Because, however, of different categorising of the mountain and foreland parts of the catchment areas, the measures are different for each kind of terrain. In the mountainous parts, belonging to national parks where nature protection is given the high priority, recultivation leads to:

- Renaturalisation of the environment, that is, bringing it to its original form, or

- Preservation of its current state.

In the foreland parts:

- Protecting towns and settlements located in the foreland from the consequences of anthropopressure, e. g.,-, from floods caused by the destruction of the vegetation cover, and

- Ensuring further functioning and development of such settlements, e. g., limiting the seasonal water deficit in the town of Zakopane.

Because of the complex genesis of the transformations, recultivation and further protection of destroyed terrains requires action on several fronts. It is necessary to join direct action affecting nature with technical-engineering work and with administrative regulations. Among the most important measures here are:

- Renovation of the vegetation cover and reconstruction of the species composition of Tatra forests;

- Regulation of streams creating flood hazard;

- Ensuring permanent utilisation of Tatra waters by the towns in the foreland;

- Water treatment;

- Restriction of pressure from the part of tourists and skiers;

- Development of the sewage and gas systems in the towns situated in the Tatra foreland.

\section{REFERENCES}

B o g a c k i M., Kow a l c z u k I., 2000, Geomorfologia ekologiczna systemów fluwialnych. Zagadnienia teoretyczne i metodyczne [Ecological Geomorphology of Fluvial Systems. Theoretical and Methodological Issues; in Polish], Wydawnictwo Akademickie DIALOG, Warszawa.

Richling A., Solon J., 1998, Ekologia krajobrazu [Landscape Ecology; in Polish], Wydawnictwo Naukowe PWN, Warszawa.

English translation: Malgorzata Mikulska 